\title{
How shall i compare thee? Comparing the prudential value of actual and virtual friendship
}

\author{
Johnny Hartz Søraker
}

Published online: 27 May 2012

(C) The Author(s) 2012. This article is published with open access at Springerlink.com

\begin{abstract}
It has become commonplace to hold the view that virtual surrogates for the things that are good in life are inferior to their actual, authentic counterparts, including virtual education, virtual skill-demanding activities and virtual acts of creativity. Virtual friendship has also been argued to be inferior to traditional, embodied forms of friendship. Coupled with the view that virtual friendships threaten to replace actual ones, the conclusion is often made that we ought to concentrate our efforts on actual friendships rather than settle for virtual replacements. The purpose of this paper is to offer a balanced and empirically grounded analysis of the relative prudential value of actual and virtual friendship. That is, do actual and virtual friendships differ when it comes to enhancing our subjective well-being? In doing so, I will discuss a number of presuppositions that lie behind common criticisms of virtual friendship. This will include, among other considerations, their potential for replacing actual friendship, as well as the possibility for self-disclosure, trust, sharing and dynamic spread of happiness in virtual worlds. The purpose is not to arrive at a firm, normative conclusion, but rather to introduce a number of considerations that we should take into account in our individual deliberations over which role virtual friendships ought to have in our unique life situations.
\end{abstract}

Keywords Virtual friendship - Subjective well-being · Computer-mediated communication · Virtual worlds . Prudential value $\cdot$ Online trust

J. H. Søraker $(\bowtie)$

Department of Philosophy, University of Twente, Enschede,

The Netherlands

e-mail: j.h.soraker@utwente.nl

\section{Background}

The purpose of this paper is to introduce a number of considerations relevant to the evaluation of the relative prudential value of virtual versus actual friendship. By 'relative prudential value', I refer to different degrees in which virtual and actual friendships can contribute to 'subjective well-being' (which I will elaborate below). By 'virtual friendship', I refer to friendships that are formed and maintained (near) exclusively by means of computermediated communication (CMC). To narrow the enquiry further, I will particularly refer to CMC in the context of virtual worlds, i.e. three-dimensional, persistent, computersimulated environments in which graphical representations of the users ('avatars') are used for communication by means of text as well as simulated bodily gestures and appearances-exemplified by Second Life, World of Warcraft and Runescape. The reason I focus on these kinds of virtual worlds is that they allow us to actually maintain a distinction between virtual and actual, in contrast with social networks such as Facebook, where it is often impossible to distinguish between virtual and actual friends. That is, friendships in virtual worlds will typically be formed and maintained entirely within the virtual world, in contrast with social network friendships, which are often formed and maintained also outside the social network. The question I will investigate, then, is whether friendships formed and maintained in virtual worlds ('virtual friendship') are less conducive to subjective well-being than traditional forms of non-mediated friendship ('actual friendship').

By way of background, I will first clarify what I refer to as the prudential value of friendship and explain how this is related to ethics. I will then introduce a number of common claims that have been made about the prudential value of 
virtual friendship. As I will argue, these kinds of claims presuppose a number of controversial background assumptions, and I will discuss one of the most important ones: whether virtual friendships actually tend to replace actual ones or not. ${ }^{1}$ On the background of all this, I will then move on to a comparison between the prudential value of virtual and actual friendship, taking both philosophical and empirical considerations into account. The ultimate purpose is not to arrive at a firm, normative conclusion, but rather to have introduced a number of important considerations that should be taken into account when considering the role virtual friendships ought to have in our individual lives, as determined by our unique opportunities and capabilities.

\section{The role of subjective well-being in ethics}

Although rarely made explicit, most criticisms of virtual friendships amount to a criticism of their conduciveness to happiness. Friendship is typically regarded as having intrinsic value, and not something we desire as amere means to an end. Indeed, having a "friend' merely as a means to an end might be seen as a contradiction in terms. That said, a fundamental reason why we go to such lengths to gain and maintain friendship is because they make us happy. Thus, when asking whether we ought to choose one type of friendship over another, one (but by no means the only) fundamental consideration is whether actual friendships are more conducive to well-being than virtual friendships. There are certainly other relevant considerations. A purely philosophical approach would be to analyze what is meant by 'friendship', whether there are necessary or sufficient conditions for something to count as a friend, as well as considerations of how friendship is related to a meaningful or virtuous life. My limited purpose in this paper is to discuss whether the differences between virtual and actual friendships correspond to a difference in their ability to make us happy. This is what I will refer to as their relative prudential value. As Tiberius makes clear, prudential value refers to "goods for a person, as opposed to moral or aesthetic values" (Tiberius 2006, p. 494). Rephrasing the question posed in this paper in its simplest form, then: Are virtual friends less good for us than actual friends; do they make us less happy? As critics have pointed out to me in the past, it is not immediately clear what this has to do with ethics so a few words of clarification are in order. ${ }^{2}$

\footnotetext{
${ }^{1}$ I discuss a number of other such presuppositions in Søraker (2010b, pp. 79-90).

${ }^{2}$ Unfortunately, there is not enough room for a full description and defence of this approach in this paper. For readers interested in (and/
}

At the most basic level, a notion of what makes us happy is necessary for any ethical theory that is grounded in some form of hedonism. For instance, Mill's famous 'greatest happiness principle' "holds that actions are right in proportion as they tend to promote happiness, wrong as they tend to produce the reverse of happiness"(Mill 1863, pp. 9-10). Clearly, as Mill himself insisted, such a theory would differ enormously depending on what we actually mean by happiness, but in most forms of utilitarianism the happiness in question is something that is experienced, hence at least partly subjective, rather than consisting of an a priori conception of what happiness is. Thus, if we ask the question of whether we ought to choose actual friendship over virtual friendship, a utilitarian analysis would have to ask the question whether there is a difference in their tendency to promote happiness.

It is quite common to criticize this kind of utilitarianism for not distinguishing between different types of pleasures, without which we would supposedly have to admit that a life of easily accessible and artificially produced pleasures is as good as a life of hard-earned, authentic pleasures. ${ }^{3}$ Indeed, this seems to be the general concern that lies behind criticism of virtual friendship; that they are somehow inauthentic hence not the kind that will provide us with genuine happiness. Although I have argued elsewhere that happiness should be regarded as a subjective mental state (Søraker 2010b), my more modest claim for this paper is that it is often essential to understand how something affects our subjective mental state of well-being if we want to investigate whether we ought to do something or not. It is important to note that this does not entail that we should always do whatever it is that we believe will make us happy. There will often be ethical reasons why we should not do something even if it contributes to happiness. Indeed, another reason why considerations of happiness are important to ethics comes from the fact that ethical dilemmas often boil down to a choice between self-interest and other-interest. Some of the most ethically challenging situations we find ourselves in - on a regular basis-consists in having to choose between my own happiness and that of others; I want to do $\mathrm{x}$ because $\mathrm{x}$ makes me happy, but I should do y instead because y makes others happy. In order to make an informed choice in these situations, it is important to know whether, or to what degree, something actually will make me and/or others happier. If I sacrifice the well-being of others for a slight or even illusory

\footnotetext{
Footnote 2 continued

or sceptical of) the relation between subjective well-being and ethics, I refer to Søraker (2010b) and my forthcoming work on the tentatively entitled "prudential-empirical ethics of technology'.

3 The 'experience machine' (Nozick 1993) and 'deceived businessman' (Kagan 1998) are some of the thought experiments intended to show the importance of authentic happiness.
} 
increase in my own happiness, this would in many cases be unethical. Similarly, whether or not it is ethically justified not to sacrifice my own well-being for the sake of others will crucially depend on whether $\mathrm{x}$ will substantially increase my well-being. Thus, the degree in which something tends to increase subjective well-being is essential for any utilitarian consideration.

It is also worth mentioning that considerations of subjective well-being by no means excludes more deontological considerations. It may very well be the case that something increases my happiness yet I am not allowed to do it. There are, for instance, many ways in which we can use someone else as mere means for our own happiness, and in such cases it is pointless to ask how happy something will make me. In other words, subjective well-being is only a relevant consideration when we are speaking of morally permissible actions, but this is often where we find ourselves. Very few would be prepared to say that virtual friendships are morally impermissible, and this is exactly why it is important to ask to what degree, if at all, our subjective well-being will be affected by replacing one with the other.

It is also essential to pay more attention to issues of well-being in ethics of technology since many (if not most) technologies have a profound effect on our well-being regardless of whether there is any wrongdoing involved. For instance, it is difficult to point fingers and speak of 'wrong-doing' when it comes to the invention of the television, yet there is no doubt that the television has affected our lives tremendously. Thus, if we are serious about wanting to evaluate and predict the intended and unintended effects of a given technology, we need to also consider its impact on subjective well-being-especially when the technology in question threatens to replace previously non-technological experiences and activities.

On this background I will proceed to discuss the difference between actual and virtual friendships when it comes to their impact on well-being - as one among more considerations that are essential for judging whether we ought not to replace one with the other. When doing so, I will partly ground my analysis in empirical research, in particular the field of 'positive psychology', which is the scientific study of what constitutes subjective well-being, and how it can be enhanced. These researchers have produced a large and valuable body of research that has been largely left untapped in applied ethics. Although one of their consistent findings is that we have a "set point" which partly determines how happy we can be, an equally consistent finding is that there are numerous 'volitional activities' that can bring us beyond our set-point of happiness (Peterson 2006, p. 97ff). These include physical pleasure, skill-demanding activities ("flow"), bodily health, acts of kindness - and perhaps most importantly, social relationships.
Empirical research does suggest that having good and lasting friendships contributes to one's well-being (at least, statistically speaking). The strength of the correlations, the consensus of meta studies (cf. Baumeister and Leary 1995; Diener and Seligman 2002; Tiberius 2008) as well as research showing that loss of close relationships have a strong and lasting effect on happiness (Clark et al. 2008) all suggest that there is a causality from the quality of our communities and relationships, on the one hand, and wellbeing, on the other. This is further suggested by Demir and Weitekamp (2007), who found a significant correlation also when controlling for differences in personality. In fact, the research findings indicate that there is a bidirectional causality between subjective well-being and the number and quality of relationships (Diener and Biswas-Diener 2008, p. 20). On this basis, two of the most influential positive psychology researchers, Ed Diener and Martin Seligman, go so far as to state that "social relationships form a necessary but not sufficient condition for high happiness - that is, they do not guarantee high happiness, but it does not appear to occur without them" (Diener and Seligman 2002, p. 83, my emphasis). ${ }^{4}$

If it is the case that friendship is essential to well-being, which there is little reason to doubt, the introduction of new venues in which to pursue friendship could be seen as something positive. These new types of friendship could simply be seen as more opportunities for establishing friendships. There are, however, numerous philosophers who have claimed that they are of less value than their actual counterparts, thus the danger is that these inferior forms of friendship replace their superior counterparts. ${ }^{5}$

\section{Common critiques of the prudential value of virtual friendship}

Hubert Dreyfus is one of many philosophers who has criticized the replacement of actual communities and friendships with virtual ones. He argues that we cannot have the same range of movements and expressions of the body in virtual communities, nor a sense of context, commitment or shared risk-taking. Furthermore, the lack of physical context fosters what he characterizes as the nihilist, irresponsible and often uninformed nature of virtual communities (Dreyfus 2004). Connecting this to the

\footnotetext{
${ }^{4}$ See Peterson (2006, p. 261) for similarly strong claims made by other researchers. It should be noted that, in contrast with the more rigorous use of 'necessary condition' common in philosophy, Diener and Seligman state that "for a variable to be necessary for happiness, virtually every happy person should possess that variable" (Diener and Seligman 2002, p. 81).

${ }^{5}$ I will return to the question of whether they actually do tend to replace online friendship below.
} 
existentialism of Nietzsche, Heidegger and Kierkegaard, he further argues that the biggest problem when it comes to virtual communities is that the lack of risk, danger, injury and "possibility of grief and humiliation" (Dreyfus 2009, p. 103) makes it impossible to make truly unconditional commitments. In the words of Friedrich Nietzsche, "the secret for harvesting from existence the greatest fruitfulness and the greatest enjoyment is to live dangerously!" (Nietzsche 1887/2007, p. 161, §283) and according to Dreyfus, sitting in front of your computer does not subject you to these important risks.

A number of arguments very similar to Dreyfus' have been put forward by other philosophers. Albert Borgmann, on the basis of a distinction between instrumental, commodified and final communities, argues that virtual communities can at best be instrumental or commodified, because they do not contain "the fullness of reality, the bodily presence of persons and the commanding presence of things" found in final communities (Borgmann 2004, p. 63). This is also reflected in Borgmann's (1984) influential notion of focal things and practices, as something that engages you not only with reality but also with others. For Borgmann, the gathering of a scattered family around the dinner table is seen as a focal practice "par excellence" (Borgmann 1984, p. 204).

In a similar fashion, Darin Barney (2004) sees virtual communities as inferior due to their lack of physical practices and Howard Rheingold argues that the lack of spontaneous bodily gestures and facial expressions is the reason for the "ontological untrustworthiness" of virtual acts of communication (Rheingold 2000, p. 177). A related argument has also been made by Langdon Winner, who argues that virtual communities ought not to be regarded as communities at all, because this ignores the importance of "obligations, responsibilities, constraints, and mounds of sheer work that real communities involve"(Winner 1997, p. 17).

Dean Cocking and Steve Matthews, in one of the most explicit philosophical criticisms of virtual surrogates as inferior, argue that virtual friendships are inferior to actual friendships because CMC eliminates non-voluntary selfdisclosure and enhances our ability to choose and control how we appear to the other-which entails that virtual friends cannot get to know each other as well as actual friends (I will return to this towards the end of the paper). Cocking and Matthews are also explicit about one extremely important point that lies behind most criticisms of virtual practices as inferior: "though we think internet 'friendship' is quite inferior to non-virtual friendship, we do not think that it is necessarily bad in itself" (Cocking and Matthews 2000, p. 224). This illustrates how the kinds of claims outlined presuppose to varying degrees that inferior virtual friendships will partly replace real ones.
That is, as long as virtual friendships are not seen as intrinsically detrimental to well-being (which few would argue), the only way in which they can be detrimental to well-being is by replacing that which is more valuable.

\section{Do virtual friends tend to replace actual ones?}

First of all, regardless of the relative value of virtual and actual friends, it would not be a widespread problem that people chose virtual friends if traditional friendship was just as easily attainable. To draw an analogy, if someone discovers that the planet Venus is made of gold, this would not be a threat to the value of gold on earth as long as it is significantly more difficult to acquire. However, virtual friendship will be easier to attain for many people, because of lack of obstacles such as physical appearance (age, gender, looks etc.), physical status indicators (cultural indicators, social status etc.) and the absence of other physical limitations such as geographical distance, physical disabilities and so forth. This presupposition clearly shows why this issue is so controversial, since the introduction of a new and easier way to get friends should be hailed as great news, if it had not been for the worry that these types of friendships are inferior. This would still not be a problem, however, if they do not tend to replace the supposedly superior types of friendship. Indeed, this entire discussion would be moot if the possibility of having virtual friends simply allowed us to have more friends than before. Thus, it is the replacement of actual for virtual that lies at the heart of the problem. I will not spend much time on this presupposition, but I just want to point out that it is far from unproblematic.

From an empirical point of view, there have been numerous studies suggesting that virtual friendships do not replace actual ones in any significant manner. A recent report on usage of screen-based technologies (TV, computers, portable devices, and so forth) concluded that although there are big differences between age groups when it comes to what type of screen-based activities we spend our time on, "total screen time was strikingly similar" (Council for Research Excellence 2009, p. 50). This suggests that the concern many parents have that children nowadays increasingly spend their time in front of a computer screen is exaggerated; that time spent in front of the computer is more likely to replace time spent in front of the TV, rather than time spent with actual friends.Another much-discussed study had a similar conclusion, but also provided evidence that (and this is what caught the media headlines): "the more time people spend using the Internet, the more they lose contact with their social environment" (Nie and Erbring 2002, p. 275). This conclusion should be taken with a grain of salt, however, since the study says 
nothing about whether the reduction in sociality was marginal or dramatic. The results are also inconsistent with most other surveys on the topic, including Hampton et al. (2009):

The extent of social isolation has hardly changed since $1985 \ldots$ internet activities have little or a positive relationship to local activity... [and] people's use of the mobile phone and the internet is associated with larger and more diverse discussion networks. And, when we examine people's full personal network-their strong and weak ties-Internet use in general [is] associated with more diverse social networks" (Hampton et al. 2009, pp. 4-5).

Citing numerous other studies, Wendy Griswold and Nathan Wright also conclude that "research exploring how the internet fits into pre-existing activities generally conclude that... the internet complements and supports offline practices rather than displacing, undermining, or competing with them" (Griswold and Wright 2004, p. 206). This is also explicitly noted by Cocking and Matthews who point out that "whether or not one's Net 'friendships' do replace one's non-virtual friendships is quite dependent on one's particular circumstances" (Cocking and Matthews 2000, p. 224). To be fair, there are also many studies that reach the opposite conclusion, but this only shows that this is an immensely complex question that is inherently contextsensitive and different for each individual - and certainly not something that can be presupposed a priori.

Despite the inconclusive empirical research, the relation between virtual and actual often seems to be chosen, intentionally or not, with a certain conclusion in mind. That is, engaging in virtual activities has been criticized on grounds of its replacement of the actual thing when the actual thing is considered to be good, but it has also been criticized on the grounds of its encouragement of the actual thing when the actual thing is considered to be bad (cf. Table 1).

Criticism of virtual activities presupposes either that the virtual replaces something good, or encourages something bad. However, the opposite line of reasoning is far from improbable-at least not a priori. If it is the case that engaging in virtual acts of violence can encourage actual acts of violence, why is it not the case that engaging in virtual communities encourages engagement in actual communities? Or, vice versa, if it is the case that engaging in virtual communities replaces engagement in actual communities, why is it not the case that engaging in virtual acts of violence replaces engagement in actual acts of violence? One way in which these relations may be inverted comes from experiencing virtual surrogates of something that is bad, and then appreciating how bad they really are. For instance, cases of virtual rape (Dibbell 2007) and other virtual crimes can in some cases make people come to realize that the horror of such crimes go far beyond physical violation alone-thereby coming to appreciate to an even higher degree how gruesome these actual crimes may be (Søraker 2010a). Closely related, we may experience virtual surrogates of what we believe is good in the actual world and come to the conclusion that it might not be worth pursuing after all-for instance fame and beauty. Again, these are difficult empirical and inherently contextdependent questions, and it is unlikely that one kind of relation holds for all cases, so we cannot simply assume that certain experiences will replace or encourage their actual counterparts. ${ }^{6}$

If, for the sake of this discussion, we do presuppose that virtual friends tend to replace actual ones, then the crucial question becomes whether virtual friendships really are inferior to actual ones. There are many ways in which to address this question, but my main approach will draw on the so-called principle of formal equality. ${ }^{7}$ The principle of formal equality states that a difference in treatment or value between two kinds of entities can only be justified on the basis of a relevant and significant difference between the two. For instance, many issues in animal ethics can be approached by first discussing the theoretical differences between humans and other animals (e.g. that some animals have significantly less developed Central Nervous System) and subsequently discuss to what degree these differences are relevant to their value (e.g. that the less developed CNS indicates little or no ability to experience pain). More generally, for something to be of more or less value than something else, the two must (1) be significantly different in one way or another, and (2) we must be able to justify why this difference entails a difference in value. Furthermore, to avoid question begging, this difference should be grounded in empirical and/or theoretical properties that are open to debate. In the remainder of this paper, I will outline what I find to be some of the most important differences between virtual and actual friendships, and discuss to what degree these differences justify a difference in value. I will do so with an eye to both empirical research and philosophical analysis, carefully weighing the benefits and shortcomings that virtual friendships may have. It is not my intention to arrive at a firm conclusion-I believe the

\footnotetext{
${ }^{6}$ To complicate matters further, whether or not virtual activities replace or encourage real activities ultimately rests on whether we presuppose an emotivist or rationalist account of the impact of virtual experiences - that is, whether virtual experiences (primarily) affect our deliberation process or our emotional dispositions. I have argued elsewhere (Søraker 2010a) that we ought to take rationalist accounts more seriously.

7 The principle is usually attributed to Aristotle (Nicomachian Ethics, V.3. 1131a10-b15; Politics, III.9.1280 a8-15, III. 12. 1282b18-23; cf. Gosepath (2008)]. See also Søraker (2007) and Wetlesen (1999).
} 
Table 1 Virtual as replacement or encouragement of good and bad

\begin{tabular}{lll}
\hline & Actual X is good & Actual X is bad \\
\hline Virtual X replaces actual X & Virtual friendships replace actual friendships & Virtual acts of violence replace actual acts of violence \\
Virtual X encourages actual X & Virtual friendships encourage actual friendships & Virtual acts of violence encourage actual acts of violence \\
\hline
\end{tabular}

matter of well-being is far too contingent upon individual life conditions for that to be possible-but my hope is that these considerations will be of use when we try to clarify the role we want virtual friends to have in our lives, and in the lives of those we care for.

\section{The relative value of actual and virtual friendships}

It is initially difficult to compare actual and virtual friendship unless we have a more concrete definition of what it is that constitutes a genuine friendship. Do virtual worlds offer us easier access to friends, hence improving our well-being, or do they only offer us inferior forms of friendship that replace genuine ones, hence reducing our well-being? As mentioned above, the principle of formal equality requires us to be precise about what it is that constitutes genuine friendship, and then discuss whether these requirements are satisfied by both actual and virtual friends. In what follows, I will discuss a number of features regarded as essential to friendship and their realizability in virtual worlds, starting with Dean Cocking and Steve Matthews' (2000) aforementioned paper on the unreality (or illusion) of close friendships in virtual worlds (or, textbased communication in general).

Cocking and Matthews roughly follow the principle of formal equality by first outlining the theoretical differences between actual and virtual friendships, and then discuss how this difference is relevant to their difference in value. In a nutshell, Cocking and Matthews claim that virtual friendships currently do not allow for non-voluntary selfdisclosure (theoretically significant difference) and that genuine friendships can only be established on the basis of non-voluntary self-disclosure (hence relevant). Furthermore, "the range of technologically based structural constraints inherent in Net communication... increase my capacity to present to others, through the presentation of my thoughts and feelings, a carefully constructed self, one that is able, for example, to concoct much more careful and thought-out responses to questions than I am able to in the non-virtual case" (Cocking and Matthews 2000, p. 228).The problem with virtual friendship, in other words, is that they are based on our ability to carefully control how we appear to the other, leading to a "friendship" that is based on an idealized version of myself rather than who I really am. Genuine friendships are created and strengthened by the numerous involuntary cues we give off about aspects of ourselves that we would typically not disclose voluntarily-aspects of ourselves that we voluntarily choose to hide or distort in online communication. According to this account, the only way to genuinely know someone is to spend considerable amounts of time in their physical presence, because physical proximity allows your friend to see who you really are, to a much higher degree than in virtual worlds. This approach to investigating the value of virtual friendships, and CMC is often referred to as the "cues filtered-out" approach (cf. Joinson 2003, pp. 25-37). When applied to virtual friendship, this raises three particularly important questions. First, to what degree can virtual worlds allow for non-voluntary self-disclosure? Second, how important is non-voluntary self-disclosure to friendship? Third, are there features of virtual worlds that can compensate for a lack (in degree) of non-voluntary self-disclosure? I will discuss these in order.

Cocking and Matthews point out that they are primarily referring to "text-based communication common to email and chat room style forums" (Cocking and Matthews 2000, p. 223 [n1]). However, their main objection to such communication is that it does not provide behavioural cues of the sort we observe in the actual world, thus it could be argued that the problems they point out apply to any kind of disembodied communication. There are, however, reasons to doubt the applicability to virtual worlds. First, virtual worlds do not allow for complete control over how we appear to others. As anyone who has communicated through virtual worlds will attest to, there is a lot of reading between the lines and interpretation going on. Users also infer information about their communication partner from cues such as delayed response, (changes in) frequency or time of day someone visits the virtual world, as well as verbal mannerisms ${ }^{8}$ and spontaneous outbursts. In a study by Patricia Wallace, it was also found that there is a large number of clues that we (consciously or not) pick up from textual communication, in particular with regard to truthfulness. Even without "the benefit of visual or auditory

\footnotetext{
$\overline{8}$ Perhaps the most common "sociolect" in virtual worlds is leetspeak, which uses various combinations of ASCII characters as replacements of traditional spellings, coupled with numerous in-jokes and references to Internet memes and catchphrases. This effectively signifies belonging to certain groups, as well as the extent to which the user is familiar with Internet technology and culture-in addition to any connotations we may have of this group of people.
} 
cues [there] was a tendency for truthful subjects to use words... somewhat more likely to be complete, direct, relevant, clear, and personalized" (Wallace 1999, pp. 52-53) and we tend to pick up on such cues even without being explicitly aware of them.

Still, Cocking and Matthews are probably right that this is not sufficient for the level of self-disclosure they regard as constitutive of genuine friendship, but there are reasons to believe that this might change in the future. There are already technologies that allow for mediation of facial expressions and other behavioural cues in virtual worlds, such as mapping facial gestures and body movements detected by the webcam and map them onto the face of the avatar. Indeed, this is one of the core activities in the open source effort to use the Microsoft Kinect technology in new and innovative ways. ${ }^{9}$ Thus, even if the criticism applies to current virtual worlds, there is reason to expect that near future virtual worlds will filter out fewer cues, hence possibly allow for some degree of non-voluntary self-disclosure as well. It should be noted, however, that there will still be a significant gap between a person's actual gestures and those projected onto the avatar, a gap that might still lead to uncertainties about how genuine the mediated facial expressions and body gestures are.

More to the philosophical argument, it is important to note that Cocking and Matthews see self-disclosure as the grounds for genuine friendship, and they regard non-voluntary self-disclosure as revealing more of our true nature. Even if we agree with the former, as most accounts of friendship would, there are reasons to disagree with the latter. Could virtual worlds afford other means of selfdisclosure that may be as revealing as non-voluntary selfdisclosure in physical proximity? Adam Briggle argues that the lack of non-voluntary cues in virtual worlds may actually be an advantage when it comes to self-disclosure. This is not a critique of the criterion as a condition for friendship, but rather an observation to the effect that we may be less likely to disclose ourselves in the actual world. In a sense, Cocking and Matthews may be right that we have more non-voluntary disclosure in the actual world, but one of the reasons we need to resort to such cues is that we often "wear masks, play roles, and fit molds" (Briggle 2008, p. 75). This point is also in line with Erving Goffman's influential sociological analysis of the performances we put on in order to guide and control how we are perceived by others (Goffman 1959). Briggle also points back to a rich tradition of philosophers who lament physical presence as an obstacle to real friendship. In the words of Ralph Waldo Emerson: "to my friend I write a letter and

\footnotetext{
${ }^{9}$ See e.g. www.kinecthacks.net for an overview of these projects. The journal Computer Animation and Virtual Worlds is also filled with similar projects (see in particular Volume 22, Issue 2-3).
}

from him I receive a letter... In these warm lines the heart will trust itself, as it will not to the tongue" (Emerson 1991, p. 230).

That we actually do disclose more of ourselves online is also in line with empirical research. For instance, in Nick Yee's (2006) comprehensive survey of 30,000 virtual world users, approximately $30 \%$ reported having told personal issues or secrets to their virtual friends that they have never told their real-life friends. A study by Bargh et al. also found "that people randomly assigned to interact over the Internet (vs. face to face) were better able to express their true-self qualities to their partners" (Bargh et al. 2002, p. 33). ${ }^{10}$ Thus, lack of non-voluntary self-disclosure can partly be compensated by a lower threshold for voluntary self-disclosure. This is complicated further if we ask whether voluntary and non-voluntary self-disclosure, even if equally disclosive, may lead to radically different types of knowledge about one's friend. This also shows that the aforementioned principle of formal equality, strictly speaking, only sets necessary conditions. If there is a theoretically significant difference between the actual and virtual world, and this difference is relevant to a difference in value, then there may still be other factors that compensate for the difference. From a purely philosophical standpoint, then, it is difficult to conclude conclusively that virtual friendships are inferior, since there are two theoretically significant differences-one positive and one negative. But there are also a number of other positive and negative theoretical differences that add to this complexity.

If we break the somewhat abstract notion of friendship into constitutive elements, one clear indication of the value of friendships comes from the value of having someone to share with. This is related to self-disclosure, but rather than being a condition for friendship, research indicates that one of the most significant determinants of well-being lies in the ability to share one's positive and negative experiences with others (Gable et al. 2004). Sharing positive experiences has been shown to increase positive emotions, and sharing negative experiences decreases negative emotions. Whether this is an inherent or instrumental value of friendship depends on whether we define friendships as necessarily consisting of sharing. Regardless, such sharing does not seem to require non-voluntary self-disclosure; we can share positive and negative experiences both voluntarily and non-voluntarily. If it is the case that we have a lower threshold for sharing through computer-mediation communication, as discussed above, then virtual friendships might indeed be seen as superior when it comes to their prudential value: their ability to increase subjective

\footnotetext{
${ }^{10}$ See also Joinson (2003, pp. 130-133) for an overview of other studies on self-disclosure through computer-mediated communication, most of which come to the same conclusion.
} 
well-being. At the very least, this is another valuable aspect of friendship where there does not seem to be any basis for judging virtual friendships as inferior to actual ones. ${ }^{11}$

Another aspect of friendship that is likely to contribute to well-being lies in increased opportunities for pleasurable experiences (again, this can be seen as instrumental or intrinsic to friendship). As Cocking and Matthews also point out, we will often "be moved to share the kind of experience with a friend we otherwise would (probably) never ourselves have chosen without invitation, not because we feel obligated, or in some way pulled against a natural urge to avoid doing it, but because this is something the friend has chosen to do" (Cocking and Matthews 2000, p. 226). Having a social network plausibly makes it easier to engage in - and discover-pleasurable experiences of various sorts. I have argued elsewhere (Sørake 2010b, pp. 216-237) that one of the problems with virtual worlds is that they give rise to fewer potentially valuable experiences. This might sound counter-intuitive given the impression of virtual worlds as the kinds of places where only imagination sets the limits for what you can do. However, it is a simple consequence of having all those experiences restricted to at most two senses-sight and sound. The numerous valuable experiences that are grounded in smell, taste and touch-as well as composite experiences requiring one or more of these-cannot presently be recreated in virtual worlds. As long as this is the case, virtual friendships will bring about a smaller range of pleasurable experiences than having actual friends. In light of these considerations, actual friendships can be seen as superior to virtual ones because an essential aspect of friendship is that they bring with them a number of other prudentially valuable experiences-and fewer of them in virtual worlds. This is also illustrated by love relationships, where the love itself is not necessarily less conducive to well-being, but actual love brings with it physical intimacy and many more shared activities, which is clearly something many people regard as essential to a good life.

There are also other differences that could affect the value of virtual friendships. Briggle (2008) points to the observation that modern living is carried out at such a frantic pace that there is less and less time for the kinds of deliberation and self-disclosure (voluntary or not) that requires time and patience. Although this is probably a

\footnotetext{
11 Another interesting question in this regard, which unfortunately lies beyond the scope of this paper, is whether there are significant differences between men and women's conversational styles that may affect the relation between communication in virtual worlds and forming/maintaining virtual relationships. For instance, Deborah Tannen (2001) has argued that women use communication as the glue that holds relationships together ('rapport-talk'), whereas men tend to maintain relationships through activities and tend to use communication more as a contest and for information ('report-talk').
}

more general problem with our culture at large, Briggle finds that it is clearly at work when we are "squeezing in e-mail or instant message exchanges while multi-tasking on one's PC" (Briggle 2008, p. 78). Briggle's complaint seems plausible enough, and there is every reason to doubt that genuine friendships could emerge in such a manner. However, this further illustrates why virtual worlds are radically different from many other types of virtuality, including discussion forums, chat rooms and social networking sites. Virtual worlds are typically not a multitasking phenomenon. Since virtual worlds demand significant amounts of processing power and bandwidth, there is little reason to be idle in a virtual world while multitasking. Indeed, leaving your avatar idle is an invitation to be robbed or killed in many virtual worlds. ${ }^{12}$ The 'singletasking' nature of most virtual worlds is also evidenced by usage statistics, which clearly show that virtual world users typically spend a significant time being active in the virtual world once they are logged in. For instance, in Second Life, users spend an average of $100 \mathrm{~min}$ in-world per visitsignificantly more than social networking sites. ${ }^{13}$ All of this indicates that virtual worlds are less vulnerable to Briggle's criticism and much more conducive to the creation of friendship than other instances of CMC.

Trust is another issue that is closely related to the value of friendship, whether we see it as something intrinsically valuable or as something necessary for genuine friendship. Trust in virtual worlds is usually more hard earned than trust in actual life. In actual life, we tend to trust people by default - at least when finding ourselves in relatively familiar and/or peaceful surroundings (cf. Løgstrup 1997; Weckert 2005). In virtual worlds, on the other hand, we usually default to distrust—or, at least, to caution. That is, most users do not trust others unless having spent considerable amounts of time with them. We can describe this as not trusting anonymous people in virtual worlds, but as we spend significant amounts of time together, as emphasized by Parks and Floyd (1996), they become pseudonymous instead. This is important because we do not simply trust (full stop); we trust someone or something. Even if we may

\footnotetext{
$\overline{12}$ For a while, in Second Life, users would be paid to have their avatars simply sit in a chair (in order to attract crowds to an establishment), which led to a host of idle avatars. However, these chairs would often be placed in casinos, so that the users would be tempted to immediately return the money they earned by losing it back to the casino owner. Thus, ever since Linden Lab banned gambling in Second Life, the existence of idle avatars has dropped dramatically.

${ }^{13}$ Cf. http://lindenlab.com/pressroom/releases/22_09_09. Average time spent in Second Life per week amounts to $760 \mathrm{~min}$, compared to 653 for World of Warcraft (http://nwn.blogs.com/nwn/2009/05/ nielsen-correction.html). It should be noted that the average hours are still inflated somewhat by passive bots (cf. http:// forums.secondlife.com/showthread.php? $\mathrm{p}=2288000$ ).
} 
not know their actual identity, through our interactions we start seeing consistent personality traits and behaviour, which gives us a more or less stable point of reference to which trust (or mistrust) can be attached. This relates to the lack of embodiment, since we have become accustomed to regard trustworthiness as a property of particular, embodied beings — and we adjust our degree of trust based on their bodily behaviour and on their bodily appearance (regrettably, in many cases). An avatar is, when first encountered, a less stable 'point of reference', because it initially reveals very little about the person behind. Consequently, "we have more difficulty (sometimes to the point of futility) of reasonably assessing the potential harm and good will of others" (Friedman et al. 2000, p. 40). Thus, in order to trust someone in virtual worlds, we need to spend comparably more time with them than in the actual world. ${ }^{14}$ This is certainly a relevant difference between actual and virtual friendship, but it is a difference that can be overcome through time-both in terms of the time we spend with other individuals and the time we spend in virtual worlds in general.

Even if virtual worlds do not necessarily preclude the possibility of trusting others, they do tend to have a reduced "climate of trust" (cf. Baier 1986, pp. 245-246). On this basis, it seems safe to conclude that virtual worlds are inferior when it comes to trust. For example, purely virtual friendships will often be less confident simply because everything you know about the person comes through CMC. In actual life, people can acquire a level of trust, or confidence, in which they have no doubt whatsoever whether the love is real or not. In a purely virtual friendship (i.e. one where there has been no physical meeting), it is hard to imagine a similar level of trust-based confidence. All of this may change if virtual worlds become a more natural part of our life where the novelty of it all no longer engenders a climate of mistrust, but this will probably require a paradigm shift of the sort that can only happen as the older generation dies out (cf. Kuhn 1996, p. 90) and gives place to what Floridi refers to as 'inforgs': "As digital immigrants like us are replaced by digital natives like our children, the latter will come to appreciate that there is no ontological difference between infosphere and Umwelt" (Floridi 2007, p. 63).

Finally, there is one important and neglected aspect of the relation between well-being and friendship that has not (to my knowledge) been discussed in the context of CMC. In a comprehensive, 20-year longitudinal study of happiness in a large social network, Fowler and Christakis (2008) came to the conclusion that people who are

\footnotetext{
14 On some occasions, this can be seen as a good thing, in particular with regard to some people's lack of trust in people from a particular cultural background, social class or similar.
}

surrounded by many happy people, in particular those who are central in the network, had a significantly higher degree of well-being. The most surprising aspect of this research, at least for our purpose, was that the most reliable indicator of spread of happiness was physical proximity. On the basis of their own research, and that of others, the authors even go so far as to state that "close physical proximity or coresidence is indeed necessary for emotional states to spread" (Fowler and Christakis 2008). This conclusion also has support from evolutionary psychology, according to which contagious expressions of happiness tend to enhance social bonds-which in turn is an evolutionary advantage. $^{15}$

If this research is correct, then this may be a very important and hitherto overlooked inferiority of virtual worlds. Because of the lack of physical proximity and physical cues that signal happiness, virtual worlds are less apt to foster dynamic spread of happiness. That said, if we get a better understanding of the neurological and perceptual mechanisms that allow for spread of happiness and other emotional states, it may be possible to instantiate these in virtual worlds as well-and use virtual worlds as a vehicle for the spread of happiness.

\section{Conclusion}

It may seem evasive not to draw a firm, normative conclusion regarding the value of virtual friendship, but this is a natural consequence of evaluating their prudential value-their value for someone. From this perspective, the conclusion must necessarily be different for different individuals. This does not mean that we have to resort to pure relativism, however. By evaluating the relative prudential value of virtual and actual relationships, we provide considerations that individuals should take into account when choosing the role virtual friendships ought to play in their own life, or in the life of their loved ones.

Among the most important considerations discussed above, we have seen that there are numerous differences between actual and virtual friendships, many of which determine their relative prudential value, but some of those differences partly compensate for each other. One way in which virtual worlds differ from actual worlds lies in the lack of (or reduced) non-voluntary self-disclosure, and both philosophical and empirical work shows that this is an important component to genuine friendship. However, it does not seem to be a necessary condition for friendship.

\footnotetext{
15 See Grinde (2002) for a comprehensive discussion of the relevance of evolutionary psychology for well-being studies. The emphasis on physically living together is also an important theme in Aristotle, perhaps most clearly seen in Politics, book III.
} 
The lack of non-voluntary self-disclosure can be (partly) compensated by increased voluntary self-disclosure, and virtual worlds allow many people to more easily express themselves due to pseudonymity. Thus, if self-disclosure forms part of the essence of friendship, as most accounts of friendship seem to agree on, and the difference between non-voluntary and voluntary disclosure does not amount to a difference in value, then virtual friendship itself is not necessarily inferior. However, friendships and communities also tend to come with a host of other aspects that tend to contribute to well-being-and there will often be fewer experiences available in a virtual world. In particular, virtual worlds have fewer options for shared experiences and pleasures, and no opportunity for physical intimacy. Thus virtual friendships, even if not strongly inferior themselves, can give rise to fewer opportunities to increase well-being. Still, we need to remember that we cannot draw conclusions that apply to everyone. Not everyone has the opportunity to easily meet new people or join communities, or to engage in the large range of activities and/or pleasures offered by actual friendships. If it is correct that "high happiness... does not appear to occur without [social relationships]" (Diener and Seligman 2002, p. 83), then virtual friendships will for some people be the only viable means to experience such happiness. One aspect that even the critics seem to agree on is that less value does not necessarily mean no value, and whether or not this is the case in one's individual circumstance will require a deliberation of the relative differences between actual and virtual friends, and whether or not those differences are relevant for you.

Acknowledgments I would like to express my sincere gratitude to the editors and the many anonymous referees for a remarkably thorough and ultimately very helpful review process. I am also indebted to Charles Ess and Philip Brey, who provided valuable feedback on earlier versions of this paper.

Open Access This article is distributed under the terms of the Creative Commons Attribution License which permits any use, distribution, and reproduction in any medium, provided the original author(s) and the source are credited.

\section{References}

Aristotle. (2009). The nicomachean ethics (D. Ross, Trans.). Oxford: Oxford University Press.

Baier, A. (1986). Trust and antitrust. Ethics, 96(2), 231-260.

Bargh, J. A., McKenna, K. Y. A., \& Fitzsimons, G. M. (2002). Can you see the real me? Activation and expression of the "true self" on the internet. Journal of Social Issues, 58(1), 33-48.

Barney, D. (2004). The vanishing table, or community in a world that is no world. In A. Feenberg \& D. Barney (Eds.), Community in the digital age: Philosophy and practice (pp. 31-52). Oxford: Rowman and Littlefield.
Baumeister, R. F., \& Leary, M. R. (1995). The need to belong: Desire for interpersonal attachments as a fundamental human motivation. Psychological Bulletin, 117(3), 497-529.

Borgmann, A. (1984). Technology and the character of contemporary life. Chicago: University of Chicago Press.

Borgmann, A. (2004). Is the internet the solution to the problem of community? In A. Feenberg \& D. Barney (Eds.), Community in the Digital Age: Philosophy and Practice (pp. 53-68). Oxford: Rowman and Littlefield.

Briggle, A. (2008). Real friends: how the internet can foster friendship. Ethics and Information Technology, 10(1), 71-79.

Clark, A. E., Diener, E., Georgellis, Y., \& Lucas, R. E. (2008). Lags and leads in life satisfaction: A test of the baseline hypothesis. The Economic Journal, 118(529), F222-F243.

Cocking, D., \& Matthews, S. (2000). Unreal friends. Ethics and Information Technology, 2(4), 223-231.

Council for Research Excellence. (2009). Video Consumer Mapping Study. Retrieved December 2, 2009, from http://www. researchexcellence.com/VCMFINALREPORT_4_28_09.pdf.

Demir, M., \& Weitekamp, L. (2007). I am so happy'cause today i found my friend: Friendship and personality as predictors of happiness. Journal of Happiness Studies, 8(2), 181-211.

Dibbell, J. (2007). My tine life: Crime and passion in a virtual world. Retrieved January 1, 2007, from http://www.lulu.com/content/ 1070691.

Diener, E., \& Biswas-Diener, R. (2008). Happiness: Unlocking the Mysteries Of Psychological Wealth. Oxford: Wiley.

Diener, E., \& Seligman, M. (2002). Very happy people. Psychological Science, 13(1), 81-84.

Dreyfus, H. L. (2004). Nihilism on the Information highway: Anonymity versus commitment in the present age. In A. Feenberg \& D. Barney (Eds.), Community in the digital age: Philosophy and practice (pp. 69-82). Oxford: Rowman and Littlefield.

Dreyfus, H. L. (2009). On the internet (2nd ed.). New York: Routledge.

Emerson, R. W. (1991). Friendship. In M. Pakaluk (Ed.), Other selves: Philosophers on friendship (pp. 218-232). Indianapolis, IN: Hackett.

Floridi, L. (2007). A Look into the future impact of ICT on our lives. The Information Society, 23(1), 59-64.

Fowler, J. H., \& Christakis, N. A. (2008). Dynamic spread of happiness in a large social network: Longitudinal analysis over 20 years in the Framingham Heart Study. BMJ, 337(dec04_2), a2338-.

Friedman, B., Khan, P. H., \& Howe, D. C. (2000). Trust online. Communications of the ACM, 43(12), 34-40.

Gable, S. L., Reis, H. T., Impett, E. A., \& Asher, E. R. (2004). What do you do when things go right? The intrapersonal and interpersonal benefits of sharing positive events. Journal of Personality and Social Psychology, 87(2), 228-245.

Goffman, E. (1959). The presentation of self in everyday life. New York: Anchor Books.

Gosepath, S. (2008). Equality. In E. N. Zalta (Ed.), The stanford encyclopedia of philosophy (Fall 2008 Edition). Retrieved December 2, 2009, from http://plato.stanford.edu/entries/ equality/.

Grinde, B. (2002). Happiness in the perspective of evolutionary psychology. Journal of Happiness Studies, 3(4), 331-354.

Griswold, W., \& Wright, N. (2004). Wired and well read. In P. N. Howard \& S. Jones (Eds.), Society online: the internet in context (pp. 203-222). London: Sage.

Hampton, K. N., Sessions, L. F., Her, E. J., \& Rainie, L. (2009). Social isolation and new technology: How the internet and mobile phones impact Americans' social networks [Electronic Version]. Pew Internet \& American Life Project. Retrieved 
January 12, 2010, from http://www.pewinternet.org/ /media// Files/Reports/2009/PIP_Tech_and_Social_Isolation.pdf.

Joinson, A. N. (2003). Understanding the psychology of internet behaviour: virtual worlds, real lives. New York: PalgraveMacMillan.

Kagan, S. (1998). Normative ethics. Oxford: Westview Press.

Kuhn, T. S. (1996). The structure of scientific revolutions (3rd ed.). Chicago, IL: University of Chicago Press.

Løgstrup, K. E. (1997). The ethical demand. Notre Dame, IN: University of Notre Dame Press.

Mill, J. S. (1863). Utilitarianism (Google Books ed.). London: Parker, Son, And Bourn.

Nie, N. H., \& Erbring, L. (2002). Internet and society: A preliminary report. IT \& Society, 1(1), 275-283.

Nietzsche, F. (1887/2007). The Gay Science (J. Nauckhoff, Trans.). Cambridge: Cambridge University Press.

Nozick, R. (1993). Anarchy, state and utopia. Oxford: Blackwell.

Parks, M. R., \& Floyd, K. (1996). Making friends in cyberspace. Journal of Communication, 46(1), 80-97.

Peterson, C. (2006). A primer in positive psychology. Oxford: Oxford University Press.

Rheingold, H. (2000). The virtual community: Homesteading on the electronic frontier. Camrbidge, MA: MIT Press.

Søraker. (2007). The moral status of information and information technologies - a relational theory of moral status. In S. Hongladarom \& C. Ess (Eds.), Information technology ethics: Cultural perspectives (pp. 1-19). Hershey, PA: Idea Group Publishing.
Søraker. (2010a). The neglect of reason-a plea for rationalist accounts of the effects of virtual violence. In C. Wankel \& S. Malleck (Eds.), Emerging Ethical Issues of Life in Virtual Worlds (pp. 15-32). Charlotte, NC: Information Age Publishing.

Søraker (2010b). The value of virtual worlds and entities-a philosophical analysis of virtual worlds and their potential impact on well-being [Dissertation]. Enschede: Ipskamp.

Tannen, D. (2001). You just don't understand: Women and men in conversation. New York: HarperCollins.

Tiberius, V. (2006). Well-being: Psychological research for philosophers. Philosophy Compass, 1(5), 493-505.

Tiberius, V. (2008). The reflective life: Living wisely with our limits. Oxford: Oxford University Press.

Wallace, P. (1999). The psychology of the internet. Cambridge: Cambridge University Press.

Weckert, J. (2005). Trust in Cyberspace. In R. J. Cavalier (Ed.), The impact of the internet on our moral lives (pp. 95-117). New York: SUNY Press.

Wetlesen, J. (1999). The moral status of beings who are not persons: A casuistic argument. Environmental Values, 8, 287-323.

Winner, L. (1997). Cyberlibertarian myths and the prospects for community. SIGCAS Computers and Society, 27(3), 14-19.

Yee, N. (2006). The demographics, motivations and derived experiences of users of massively-multiuser online graphical environments. Presence: Teleoperators and Virtual Environments, 15(3), 309-329. 